\title{
História da educação escolar brasileira: instrumento de inclusão e/ou exclusão social?*
}

Recebido em: 24/03/2011

Aceito em: 26/07/2011

Elciclei Faria dos Santos ${ }^{1}$

Laura Daniel ${ }^{2}$

David Lopes $\mathrm{Neto}^{3}$

O texto parte de uma breve discussão acerca do que é educação, das mutações que essa sofreu ao longo do processo histórico, de seu papel na sociedade e do caminho percorrido no Brasil até os dias atuais, levando em consideração os interesses que impulsionaram e influenciaram ações e projetos de inclusão social. Em seguida, fazemos uma reflexão sobre o papel da educação associado à mudança social em oposição ao discurso neoliberal e em favor de quem e para que existe o processo educativo. Por fim, realizamos uma discussão sobre a educação como mercadoria na chamada "era do conhecimento" e os descaminhos dessa sociedade do conhecimento, que inclui e exclui ao mesmo tempo ou que inclui de maneira excludente.

Descritores: Educação, História, Política, Estudantes.

\section{History of Brazilian school education: a tool for inclusion and / or social exclusion?}

This article takes a brief discussion of what is education, changes which it suffered during the historical process, their role in society and in Brazil's path to the present day, taking into account the interests that propelled and influenced actions and social inclusion projects. What follows is a reflection on the role of education associated with social change in opposition to the neoliberal discourse and for whom and for what exists, the educational process. Finally, we held a discussion on education as a commodity in the called "knowledge era" and the waywardness of this knowledge society, which includes and excludes at the same time or in a manner that includes exclusively.

Descriptors: Education, History, Policy, Students.

\section{Historia de la educación escolar en Brasil: una herramienta para la inclusión y / o exclusión social?}

Este artículo realiza una breve discusión acerca de qué es la educación, los cambios que sufrió durante el proceso histórico, su papel en la sociedad y el camino percurrido en Brasil hasta actualidad, teniendo en cuenta los intereses que han impulsado e que influenciaron las acciones y proyectos de inclusión social. Lo que sigue es una reflexión sobre el papel de la educación relacionado con el cambio social en oposición al discurso neoliberal y para quién y para qué existe, el proceso educativo. Por último, se celebró una discusión sobre la educación como una mercancía en la "era del conocimiento" y el desvío de esta sociedad del conocimiento, que incluye y excluye al mismo tiempo o lo que incluye de manera que excluye.

Descritores: Educación, Historia, Política, Estudiantes.

\section{INTRODUÇÃO}

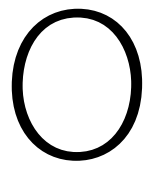

\section{que é educação?}

A questão da educação que queremos discutir neste texto prescinde de uma abordagem interdisciplinar a partir de conhecimentos das áreas da educação, história, filosofia, sociologia e antropologia, na perspectiva de compreender de que forma a educação escolar tem sido, historicamente, instrumento de inclusão e/ou exclusão social.

Mais recentemente, a educação tem despertado interesse de cientistas de várias áreas do conhecimento, apontando-a como um dos instrumentos necessário às mudanças e transformações sociais, políticas, econômicas e culturais. A comunidade científica - embora tardiamente - começou a perceber que a forma cartesiana de conhecimento cunhada na era moderna não conseguiu apreender nem dar respostas à realidade complexa em que vivemos.

Compreendemos que a educação é uma prática eminentemente humana. É através dela que as gerações repassam saberes, valores, crenças e técnicas que querem manter vivos entre as gerações mais novas, transformando assim a natureza e a própria vida.

Desde o momento do nascimento, o ser humano dedica parte de sua vida à educação. Brandão(1) salienta que a educação se faz em casa, na rua, na igreja, na escola, e que, de um modo ou de muitos, envolvemos parte de nossa vida com ela: para aprender, para ensinar, para saber, para fazer, para ser ou para conviver. Não há uma forma única nem um único modelo de educação; a escola não é o lugar exclusivo onde ela acontece e talvez nem seja o melhor; o ensino escolar não é sua única prática e o professor profissional não é seu único praticante.

O termo educação designa a transmissão e o aprendizado das técnicas culturais - as técnicas de uso, produção e comportamento - pelas quais um grupo humano poderá satisfazer suas necessidades, proteger-se contra a hostilidade do ambiente físico e biológico e trabalhar em conjunto, de modo mais ou menos ordenado e pacífico ${ }^{(2)}$. Essa definição

1 Pedagoga. Mestre em Educação pela Universidade Federal do Amazonas.

2 Socióloga. Mestre em Ciências Sociais pela Universidade Estadual Paulista.

3 Enfermeiro. Doutor em Enfermagem. Professor da Universidade Federal do Amazonas. E-mail: david.netto@uol.com.br.

* Texto elaborado como requisito final da disciplina Desigualdade e Exclusão Social em Espaços Urbanos, do Programa de Pós-Graduação em Saúde, Sociedade e Endemias na Amazônia (Parceria entre Universidade Federal do Amazonas, Centro de Pesquisa Leônidas e Maria Deane/Fiocuz e Universidade Federal do Pará). 
de educação está relacionada às experiências das primeiras sociedades, que se propunham a repassar técnicas consideradas válidas e na transmissão simultânea da crença do caráter sagrado e imutável dessas técnicas. Abbagnanno(2) diz que ainda cabe à educação a tarefa não só de transmitir técnicas, mas também de corrigi-las e aperfeiçoá-las de modo diverso nas distintas sociedades. A transmissão das técnicas por meio da educação tem por finalidade aperfeiçoá-las pela iniciativa dos indivíduos. Assim, a educação não é definida do ponto de vista da sociedade, mas do indivíduo: sua formação e sua cultura tornam-se o fim da educação.

Podemos distinguir a educação informal da educação formal. A primeira é aquela que recebemos em casa, na família, na comunidade, na igreja, nos grupos, na mídia, nas brincadeiras. É assim chamada por não ser organizada nem seguir normas, regras, conteúdos e tempo rígidos. A educação formal é aquela praticada nas escolas, que pressupõe organização, planejamento, regras e conteúdos rígidos, que necessita de profissionais especializados.

Assim como a humanidade, a educação também passou - e ainda passa - por processos de transformação ao longo do tempo. Salienta-se que, a partir do momento em que a educação deixa de ser comunitária e começa a gerar hierarquias sociais, o saber comum se divide, começa a ser distribuído de forma desigual e passa a reforçar a diferença entre os membros do grupo, ou seja, "é o começo de quando a sociedade separa e aos poucos opõe: o que faz, o que se sabe com o que se faz e o que se faz com o que se sabe"(1).

Vejamos um conceito de educação do sociólogo francês Durkheim: “A educação é a ação exercida pelas gerações adultas sobre as gerações que não se encontram ainda preparadas para a vida social; tem por objetivo suscitar e desenvolver na criança certo número de estados físicos, intelectuais e morais reclamados pela sociedade política em seu conjunto e pelo meio especial a que a criança, particularmente, se destina (apud Brandão, 2003) $)^{(1) " .}$

Durkheim diz que a educação como prática social tem como origem e destino a sociedade, com seus modos próprios de educar, diferentes de uma cultura para outra, necessários à vida e à ordem da sociedade. Ele buscou esclarecer de que forma a cultura e a sociedade funcionam e qual a função da educação dentro delas, evidenciando que é através dela que a sociedade reproduz os tipos de sujeitos de que ela necessita.

Durkheim preconiza que a educação atua sobre os modos de vida e o crescimento da sociedade em dois sentidos: 1) no desenvolvimento de suas forças produtivas; 2) no desenvolvimento de seus valores culturais. Assim, o surgimento e a evolução de diferentes tipos de educação dependem da existência de fatores sociais determinantes e de suas transformações. O modo como os seres humanos se organizam para produzir os bens com que reproduzem a vida, a ordem social de convivência e o lugar que cada sujeito ocupa na sociedade determinam as ideologias e as normas com que a sociedade se organiza. Determina também o tipo de educação que dada sociedade coloca em prática.

Logo, a escola surge no momento em que a sociedade se torna mais complexa, quando a produção dos bens ultrapassa a necessidade imediata de consumo do grupo, passando a gerar excedentes ${ }^{(3)}$. Nessa época, a divisão social do trabalho tende a acentuar as diferenças sociais e o saber torna-se privilégio de uma minoria rica. A escola surge como instrumento de transmissão do saber acumulado, restrito apenas a alguns. Podemos então aferir que sua natureza e importância variam de acordo com o tempo, dependendo das necessidades históricas, políticas e socioeconômicas dos grupos onde ela está inserida.

Não podemos deixar de dizer que a educação escolar surge nos grupos e sociedades de acordo com suas necessidades socioeconômicas, históricas e políticas. A educação muda e sofre mudanças ao longo do tempo, mas não consegue atender a todos igualmente. Para comprovar essa tese, basta olharmos para a história da educação no mundo e no Brasil. Daí afirmarmos que ela pode ser instrumento tanto de inclusão quanto de exclusão social.

No Brasil colonial no século 16 , as primeiras escolas estavam a cargo de missionários católicos, sobretudo os jesuítas, que reuniam os filhos dos colonos e dos índios. A educação escolar jesuítica tinha objetivos antagônicos ao separar os catequizados e os instruídos. Os filhos dos índios, cabia catequizar e pacificar, tornando-os dóceis para o trabalho; os filhos dos colonos, cabia instruir, ou seja, ensinar a ler e escrever. A educação escolar dessa época era instrumento de inclusão ou de exclusão social? Quem estava excluído da escola?

A educação escolar brasileira do século 17 continuava sob o monopólio dos jesuítas, que desprezavam a revolução intelectual e científica. Havia uma ampla rejeição do ensino das ciências físicas e naturais, assim como a técnica e as artes. Visavam a dar uma formação humanística, centrada no latim, nos clássicos e na religião. Essa educação escolar interessava apenas a uma minoria da classe dirigente, somente para adquirir erudição. Quem estava excluído da educação escolar? Nessa época, as mulheres, os negros e os índios encontravamse excluídos ${ }^{(3)}$. Um pouco mais tarde, uns poucos "mulatos" reivindicaram o acesso à educação. Nesse contexto, os graus acadêmicos assumiam destacada importância na classificação social, o que significou o aumento da procura dos mestiços pela escola, provocando um conflito conhecido como "questão dos moços pardos".

No século 18, a educação escolar, que estava sob o domínio da Igreja durante aproximadamente 210 anos, sofreu um profundo abalo com a expulsão dos jesuítas do Brasil, em 
1759. Mesmo que se questionem seus métodos, os jesuítas tinham construído uma estrutura de ensino que foi totalmente desmantelada, e isso significou um retrocesso no ensino.

De acordo com Aranha ${ }^{(4)}$, a reconstrução da estrutura do ensino brasileiro só foi iniciada pelo marquês de Pombal depois de uma década. Algumas iniciativas existiram, mas as medidas só se efetivaram com a implantação do ensino público oficial, em 1772. As elites mandavam seus filhos para completar os estudos na Europa, enquanto aumentava o analfabetismo e o ensino era cada vez mais precário.

A atuação dos jesuítas foi mais contundente na formação da burguesia e das classes dirigentes, visto que a sociedade agrária da época não exigia especialização, pois o trabalho estava a cargo de mão-de-obra escrava. Nesse contexto, a elite era preparada de forma intelectual e universalista, distante das conquistas científicas da idade moderna e da realidade brasileira. $O$ ensino continuava exclusivo para uma minoria privilegiada. No século 19, o Brasil consolidou o modelo agrário-comercial e fez as primeiras tentativas de industrialização(4). Com isso, houve um surto industrial, a burguesia urbano-industrial se fortaleceu, a política imigratória teve início, a escravidão foi abolida e a república, proclamada. A educação recebeu influência do positivismo na luta pela escola pública, leiga e gratuita, assim como o ensino das ciências. Com isso, priorizou-se o ensino superior em detrimento dos outros níveis de ensino, mantendo o privilégio das elites dominantes. Grande parte da população encontrava-se excluída da educação escolar.

A educação escolar brasileira sofreu várias reformas ao longo do século 20 , e essas eram estabelecidas de acordo com as mudanças no contexto político, social e econômico. A partir da década de 30, a educação passou a receber maior atenção, quando foi criado o Ministério da Educação e Saúde, que alavancou o planejamento da educação e a estruturação das universidades. Nessa época, começou a era Vargas, e o país estava passando pela crise do modelo agro-exportador para o delineamento do modelo nacional-desenvolvimentista, baseado na indústria, o que exigia maior escolarização.

Com o advento da Revolução Industrial e os desdobramentos do capitalismo, a pedagogia foi convocada a rever seus princípios. Nesse contexto, a educação escolar passou a ser um instrumento exigido pela "sociedade do trabalho" e pela "sociedade científica e tecnológica" para formar mão-de-obra especializada para o mercado de trabalho, já que se encontrava separada da vida e desligada da realidade ${ }^{(5)}$.

Das mudanças ocorridas no país durante o século 20, destacamos a luta pela ampliação da oferta de ensino, o que significa um avanço, mas não conseguimos um ensino de qualidade para todos, visto que ainda existem pessoas excluídas da educação básica e da sociedade de modo geral. A escola dual continua existindo e exclui a maioria da população.
Quando falamos de exclusão da educação escolar, não queremos nos deter, aqui, apenas no processo educativo além dos muros da escola, mas também a exclusão dentro da escola, na sala de aula. Um espaço de inclusão, de partilha, de elucidação, de formação ética, de libertação. A educação escolar em favor das classes dominantes é algo que perpassa espaços de tempo, lugares e gerações, reforçando a prática de que cada um tem a escola e a educação que merece ter.

As diferentes categorias de sujeitos (sociopolítico-sociais) estão inseridas no processo educativo (recebendo e transmitindo informações), de acordo com sua posição social no sistema político de relações do grupo, através da divisão social do saber e dos agentes usuários do saber. Ao passo que todos aprendem a ser "gente", "adulto", "homem", "mulher", outros aprendem a assumir o papel de "chefes", "dirigentes", e outros, ainda, de "escravos"(1).

É possível pensar a educação escolar somente a partir do interesse das classes dominantes? E os interesses das classes menos privilegiadas? Os projetos educacionais utilizados nas escolas brasileiras, de Manaus, são pensados para atender todos os tipos de pessoas? Estariam voltados para a inclusão ou exclusão da maioria dos estudantes?

\section{A educação escolar} em favor das classes dominantes é algo que perpassa espaços de tempo, lugares e gerações, reforçando a prática de que 'cada um tem a escola e a educação que merece ${ }^{\prime \prime \prime}$
A educação associada à mudança social Muitos pensadores na atualidade defendem que a educação não serve apenas à sociedade ou à pessoa, mas que ela representa um dos principais meios de mudança social e/ou de adaptação no mundo em constante mudança. Essa ideia aparece de forma explícita ou velada nas leis do ensino e nos programas educacionais.

A ideia de educação permanente de que muito se ouve falar nos discursos neoliberais está intimamente ligada à lógica de que, se a sociedade está em constante mudança, as pessoas precisam se atualizar em "reciclagem" de conhecimentos para acompanhar e readaptarse às mudanças que estão ocorrendo no mundo e, sobretudo, na economia. Não é raro o discurso de que as sociedades estão vivendo a "era do conhecimento e da informação". Como acompanhar se as mudanças são em espaços de tempo cada vez menores? O que será da criança, do jovem e do adulto que nem sequer consegue acompanhar os conteúdos que as escolas oferecem? A escola está ensinando ou certificando?

Na perspectiva da educação como mudança social, temos os pensadores que acreditam que ela tem o poder de transformar a sociedade. Em parte, é correto afirmar que a educação é um dos instrumentos que podem despertar a consciência e a prática de mulheres e homens para a mudança social, mas ela não é o único instrumento de transformação das estruturas sociais, visto que é determinada e sofre o controle dessas mesmas estruturas.

A educação tem impulso para vencer paradigmas e derrubar os muros das desigualdades, na ânsia de uma sociedade justa e democrática. As perguntas que poderiam pautar todo e qualquer processo educativo poderiam ser: em favor de que estudo? Em 
favor de quem? Contra que estudo? Contra quem estudo ${ }^{(6)}$.

\section{A educação como mercadoria na era do conhecimento: a exclusão do saber?}

A ideologia do crescimento econômico, aliada ao neoliberalismo nas últimas décadas do século 20, uniu de forma contundente a educação escolar à economia, ou seja, a educação virou mercadoria que pode ser vendida em pacotes oferecidos na presença dos consumidores e até a distância. O século 21 parece vir consolidar esse fato.

A desigualdade no acesso à educação escolar de boa qualidade é evidente no Brasil neoliberal. A educação foi transformada em mercadoria que se compra e vende nas prateleiras dos supermercados, nas faculdades e universidades que se multiplicam diuturnamente nas grandes, médias e até mesmo nas pequenas cidades, nos supermercados das escolas que prometem levar os jovens às melhores universidades do país - que, mesmo sucateadas, são as universidades públicas estaduais e federais, porque as universidades privadas, que vendem seus produtos a preços abusivos e ainda recebem incentivo público, o fazem de forma deficiente, como têm revelado os resultados dos provões; supermercados de livros didáticos e não-didáticos na disputa editorial; supermercados de mídias com a mais alta tecnologia para auxiliar e estimular professoras, professores e estudantes, enfim, mídias que surgem com o propósito de auxiliar no aprendizado.

Desde o fim do século 19, o mundo imaginava que o ano 2000 seria o coroamento do processo civilizatório. Nesse sentido, pensava-se a educação como o ápice desse processo - uma sociedade altamente tecnológica, utilizando-se da alta tecnologia em saúde, transportes, lazer, cultura e educação. No entanto, o século 21 trouxe, junto com o avanço tecnológico, a desigualdade socioeconômica e, aliada a ela, a exclusão social de milhões de pessoas ${ }^{(7)}$.

O estreitamento das relações por meio da internet e o encurtamento de distâncias, antes nunca imaginado, não chegam ao alcance da maior parte da população. Nos grandes centros urbanos, podemos ver escolas que incentivam seus estudantes a fazer uso da internet e, através de mídias interativas, ensinam e incitam a pesquisa, ao passo que crianças e adolescentes desses mesmos grandes centros urbanos nunca chegaram perto de um computador. A ideia de inclusão digital ainda está muito longe de se concretizar. A exclusão digital vem a constituir mais uma das diversas faces da exclusão social.

É fato que há uma distinção entre exclusão social e pobreza. Por conter elementoséticose culturais, a exclusão social se referetambém à discriminação e estigmatização( ${ }^{(8)}$. O Brasil, país pluricultural que concentra uma enorme diversidade de povos e culturas e um grande contingente de pobres, os mantém excluídos da sociedade, dos bens e dos benefícios que deveriam ser distribuídos de forma igualitária entre os grupos em nome da justiça social.
A realidade nos mostra que a educação básica pública brasileira não é de qualidade, e essa má qualidade gera exclusão social, sem que isso esteja totalmente aliado à pobreza, visto que existem filhos de ricos matriculados em escolas públicas. A exclusão se dá pelas condições desiguais de acesso, permanência e continuidade, assim como pelos conhecimentos veiculados nas escolas, que muitas vezes são alheios à realidade das classes menos favorecidas.

Com isso, temos a exclusão no acesso a bens e serviços de boa qualidade, que deveriam ser básicos para o desenvolvimento de qualquer país. A ausência de acesso a determinado serviço ou o acesso a um serviço de má qualidade gera discriminação e estigmatização, pois a educação básica de má qualidade impede a inserção de jovens oriundos de escolas públicas, em pé de igualdade com jovens oriundos de escolas privadas, no acesso às vagas nos cursos de universidades públicas, a empregos e às oportunidades que se apresentam.

As chamadas ações afirmativas, como as cotas para estudantes de escolas públicas, negros e índios nas universidades, assim como o Programa Universidade para Todos (ProUni), não atendem a toda a demanda. Ainda que seja uma importante iniciativa a fim de minimizar a desigualdade social no acesso à educação, acaba por discriminar e estigmatizar os que conseguem ingressar no ensino superior por meio dessas ações.

Discrimina porque a desigualdade de acesso à educação no Brasil não será resolvida com ações isoladas. O sistema de cotas para índios, por exemplo, é um problema que já está se revelando, visto que permite o acesso, mas não garante a permanência e continuidade, o que está gerando o abandono do curso por parte do estudante que, na maioria das vezes, passou por um processo de escolarização "inferior" e por isso tem dificuldade para acompanhar e prosseguir nos estudos. Além disso, frequentemente, muitos têm sido vítima de preconceito por parte de colegas, funcionários e professores.

No que se refere ao sistema de cotas para estudantes de escolas públicas, a realidade mostra que as classes privilegiadas estão se utilizando desse recurso em benefício próprio. Como isso ocorre? Muitas famílias de classe média e ricas matriculam seus filhos em escolas públicas e ao mesmo tempo pagam professores particulares, cursinhos preparatórios e cursos de línguas, o que Ihes dá um diferencial e, por estarem mais bem preparados, acabam conquistando as vagas nos cursos mais concorridos das universidades públicas. A quem, de fato, o sistema está excluindo?

Outra ação que queremos destacaré o Programa Universidade para Todos (ProUni), criado pelo governo federal em 2004, que tem por finalidade "a concessão de bolsas de estudo integrais e parciais em cursos de graduação e sequenciais de formação específica em instituições privadas de ensino superior"(9).

O que queremos problematizar é a posição do governo em oferecer isenção de tributos em contrapartida às instituições 
que aderirem ao programa. Isso, a nosso ver, é uma forma de premiar as instituições privadas e punir as instituições públicas, visto que as instituições privadas ficam em dia com a Receita Federal e ainda recebem recursos para o pagamento de bolsas que deveriam ser destinadas às instituições públicas.

Na realidade, o ProUni é uma das estratégias utilizadas pelo governo brasileiro na tentativa de atingir uma das metas do Plano Nacional de Educação (PNE), que prevê a oferta de educação superior que pretende atingir até 2011 - cerca de $30 \%$ dos jovens entre 18 e $24 \operatorname{anos}^{(9)}$. Não vamos nos iludir com as propagandas, pois sabemos que os organismos internacionais que financiam projetos de educação exigem resultados satisfatórios em prazos mínimos por meio de projetos de educação voltados apenas para a certificação dos estudantes.

O Estado brasileiro neoliberal consolida uma dada concepção de inclusão não afiançando a garantia de direitos sociais em suas ações: caracteriza as atenções sociais como concessões partilhadas como filantropia da sociedade e não assumidas como responsabilidade pública. Trata-se de uma forma "truncada" ou "escolhida a dedo" da "inclusão social"(8).

A dinâmica da sociedade do conhecimento é feita de modo preponderante pelo marcado neoliberal.

Em termos teóricos, estaríamos vivendo agora a "maisvalia-relativa", como assinalava Marx, fundada em ciência e tecnologia, ou seja, a produtividade econômica é alimentada essencialmente, não mais pela força física do trabalhador, mas por sua inteligência. $E$ ao neoliberalismo interessa a educação e o conhecimento porque o lucro está diretamente ligado à inovação tecnológica(10).

Vemos que as expectativas de que a globalização traria benefícios a toda a população mundial, ou pelo menos para grande parte dela, caiu por terra. Se estivermos vivendo na chamada "sociedade do conhecimento", ou ainda "sociedade da informação", quem é que tem acesso ao conhecimento e à informação? A lógica neoliberal nos mostra claramente que o conhecimento e a informação são comprados nas mais diversas instituições de ensino, nas escolas de educação formal, nas escolas de informática, mas escolas de línguas e nas universidades. Mas, na lógica do mercado neoliberal, só pode comprar quem tem dinheiro. Assim, as pretensões universalizantes do conhecimento, tão bem expressas na ideia de universidade, redundaram no aprisionamento ostensivo de suas energias no mercado, assinalando que o efeito redistributivo é, como regra, inverso ${ }^{(11)}$.

O risco de manipulação é intrínseco à sociedade da informação, mas é no risco que podemos reduzir a manipulação. A sociedade da informação informa bem menos do que se imagina, assim como a globalização engloba as pessoas e povos bem menos do que se pretende. Na sociedade da mercadoria, a mercadoria vem antes ${ }^{(11)}$

Estamos cientes, como já nos antecipava Platão, que aprender é saber pensar. Mas como pensar em um meio social que agride, estigmatiza, exclui e aliena? A má administração pública nos apresenta falhas exorbitantes no sistema educacional, seja na infraestrutura, seja na ausência de programas que levem em conta o conhecimento tácito trazido pela criança, pelo adolescente, pelo jovem ou pelo adulto.

Já vimos que, historicamente, existe dualidade no ensino brasileiro, onde se estabeleceu uma escola para os ricos e outra para os pobres. Sabemos que nenhuma sociedade se desenvolve sem que haja investimento na educação. Como podemos lutar para que a educação se transforme num instrumento de inclusão social? E como falar de inclusão social num país onde a maioria da população se encontra excluída, sem moradia, alimentação, segurança, lazer, saúde, educação?

Entendemos que nosso compromisso como educadoras e educadores no século 21 deverá transcender a lógica do mercado neoliberal. Precisamos conhecê-lo e compreendêlo, já que estamos inseridos nele, mas a meta é alcançar nossa cidadania e a cidadania das pessoas excluídas. Dessa maneira, a educação não deverá apenas formar mão-de-obra para atender às necessidades do mercado, mas formar cidadãs e cidadãos conscientes de sua condição para que, juntos, possamos lutar por uma sociedade mais justa.

\section{Referências}

1. Brandão CR. O que é Educação. 42a ed. São Paulo: Brasiliense; 2003.

2. Abbagnano N. Introdução ao existencialismo. São Paulo: Martins Fontes; 2000.

3. Aranha ML. A história da educação. 2a ed. São Paulo: Moderna; 1996.

4. Aranha ML. Filosofia da educação. 2a ed. São Paulo: Moderna; 1996.

5. Ghiraldelli Júnior P. Pedagogia e infância em tempos neoliberais. In:

Ghiraldelli JRP, (organizador). Infância, educação e neoliberalismo. 2a ed. São

Paulo: Cortez; 2000

6. Freire P. Pedagogia da autonomia: saberes necessários à prática docente.

28a ed. São Paulo: Paz e Terra; 1996.

7. Buarque C. A questão social do século XXI. In: Anais do VIII Congresso Luso-
Afro-Brasileiro de Ciências Sociais, Coimbra, Portugal, 2004.

8. Sposati A. Exclusão social abaixo da linha do Equador. In: Seminário

Exclusão Social, PUC, São Paulo, 1998.

9. Ministério da Educação (BR). Programa Universidade para todos [Internet].

[citado em 2008 Dez 11]. Disponível em: http://portal.mec.gov.br/prouni/

index.php?option=com_content\&task=view\&id=124\&ltemid=140.

10. Demo P. A educação do futuro e o futuro da educação. Campinas, SP:

Autores Associados, 2005.

11. Demo P. Ambivalências da sociedade da informação. In: Rev Ciênc Inform. 2000;29(02). 